\title{
En återuppstånden runsten från Källa ödekyrka på Öland (Öl 57)
}

\author{
Magnus Källström (Riksantikvarieämbetet)
}

\begin{abstract}
This paper discusses the relationship between the now lost runestone fragment Öl 57 from Källa Old Church and some later finds of runestone fragments from the same place. Similarities between these fragments show that they originally must have belonged to the same stone, which also makes it possible to reconstruct part of the inscription and obtain a better understanding of the original monument.
\end{abstract}

Keywords: Runic inscriptions, Viking Age, Öland, runestone

$S_{\text {ö }}^{a}$ amnordisk runtextdatabas upptar tre vikingatida runstenar från Källa ödekyrka på Öland: Öl 56, Öl 57† samt några mindre runstensfragment funna 1960. De senare kan enligt Ragnhild Boström $(1969,288)$ ha tillhört samma runsten som den försvunna Öl 57, men de har i databasen ändå fått ett eget signum: Öl SvK128;288. Denna uppdelning upprätthålls ännu av Cecilia Ljung (2016, 2: 93-95).

Runstenen Öl 57† är endast känd genom Jonas Håkansson Rhezelius, som avbildade den under sin antikvariska resa på Öland 1634. Stenen utgjordes redan då av ett fragment (fig. 1). I den endast halvsideslånga artikeln i Ölands runinskrifter (SRI, 1: 125) citerar Erik Brate ett långt stycke från Rhezelius' anteckningar, som lyder:

Källda socken; Sammastädes widh Norre Kliifstätan; frå sitt forna rum, och högh förd. På thenna runsten fins intet mere, än som nu på sielfva afrijtningen synes. Och är Notabilis därföre att härpå är linea lapidis, och verba runica, medh uphögdt arbete hugget. Wore märkeligit, om mann flere Runestenar finna kunde, medh ophögdt arbete, det näpligen hända kan. Desse två Runstenar wiste ingen af, utan nu i åhr upfundne.

Källström, Magnus. "En återuppstånden runsten från Källa ödekyrka på Ỏland (Öl 57)."

Futhark: International fournal of Runic Studies 9-10 (2018-2019): 179-191.

English: "A resurrected runestone from Källa Old Church on Öland (Öl 57)."

DOI: $10.33063 /$ diva-401071 


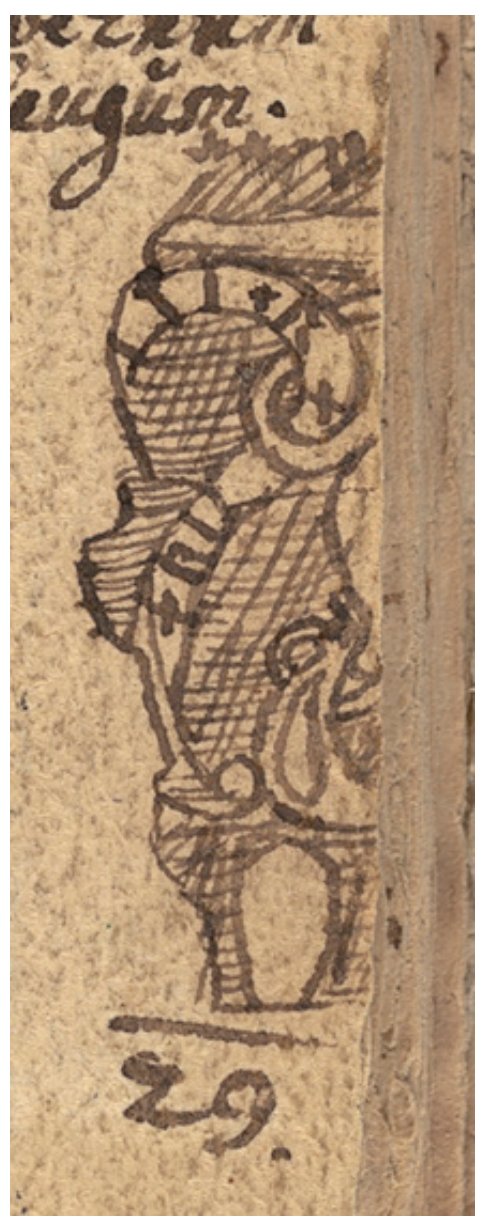

Fig. 1. Runstensfragmentet Ỏl 57 avbildat av Jonas Håkansson Rhezelius 1634 i F c 5 (Kungliga biblioteket). Foto: Kungliga biblioteket, Stockholm.

Det framgår här att stenen har varit huggen i relief, något Rhezelius tydligen inte hade stött på tidigare. Av själva inskriften återstod dock inte mer än åtta runor i rundjurets svans, varav de flesta tycks ha varit mer eller mindre oläsliga, men där åtminstone $\times \mathbf{r a}$ och en avslutande $\mathbf{a}$-runa kunde urskiljas. Detta är vad som är känt av inskriften på Ỏl 57 och det är naturligtvis omöjligt att tolka.

Brate har i slutet av artikeln tillfogat en i sammanhanget något förbryllande uppgift, där han efter J. G. Liljegrens Run-urkunder (1833, 143) anför ett stycke av en längre och mer lättförståelig inskrift som ska ha funnits i "N. kyrkogårdsmuren" i Källa: 
L. 1292 är ... lit • rita • stai ... . - . sial. . men så har den inskrift som teckningen hos Rhezelius framställer, icke kunnat lyda, då den utgör slutet af en inskrift.

Brate ger ingen förklaring till skillnaderna mellan uppteckningarna. Den inskrift som Liljegren har citerat kommer från Abraham Ahlqvists Ölands historia och beskrifning, dit han också hänvisar. Ahlqvist (1822-27, 2, 1: 95 f.) beskriver här först det av Rhezelius avbildade fragmentet, som då var försvunnet, varefter han tillfogar (s. 96): "För tjugo år tillbaka uttogs ur norra kyrkogårdsmuren ett stycke af en Runsten med desse tecknade Runor: lit. rita. stai. - - - - sjal. - - - - ". Den aktuella delen av Ahlqvists arbete trycktes 1825 och fyndet bör alltså ha gjorts omkring 1805. Någon teckning av stenen eller uppteckning av inskriften med runor har tyvärr inte kunnat uppspåras i hans efterlämnade samlingar i Uppsala universitetsbibliotek.

Ahlqvist säger inget om att fragmentet skulle ha tillhört samma runsten som det tidigare kända och hos Liljegren är de upptagna under olika nummer. Det fragment som omnämns av Ahlqvist återfinns som nämnts under nr 1292, medan det av Rhezelius avbildade fragmentet har fått nr 1567 och är placerat under rubriken "Runstoder”. Liljegren har där anmärkningen "Ristningen i upphöjdt arbete", vilket förmodligen är motivet till att stenen har förts till denna avdelning. Det märkligaste är dock att inskriften på detta fragment uppges lyda ” - ..t iera.. -”, vilket ju har mycket litet gemensamt med de runor som finns på Rhezelius' teckning. Liljegren hänvisar dock uttryckligen till Rhezelius, och i "Fullständig Bautil" (ATA) har han klistrat in en teckning av fragmentet, vilken är försedd med följande anteckningar (fig. 2):

Vid Källa på Öland i kyrkogårdsmuren af tälgsten hvitaktig.

Af denna finnes ej mera än detta stycket, som är märkligt deraf att Runor och lineer äro upphöjdt arbete.

Funnen och afritad af Rhez d. 15 aug. 1634.

Läsningen avviker något från Rhezelius genom att den andra runan har återgivits som $\mathbf{t}$, men det verkar ändå troligt att det handlar om en direkt kopia av hans teckning. Det är också tydligt att texten " - ..t iera.. - ” i L 1567 bygger på de inledande runorna i den uppteckning som finns på detta ark, där alltså skiljetecknet efter den tredje runan har omtolkats som en e-runa. 


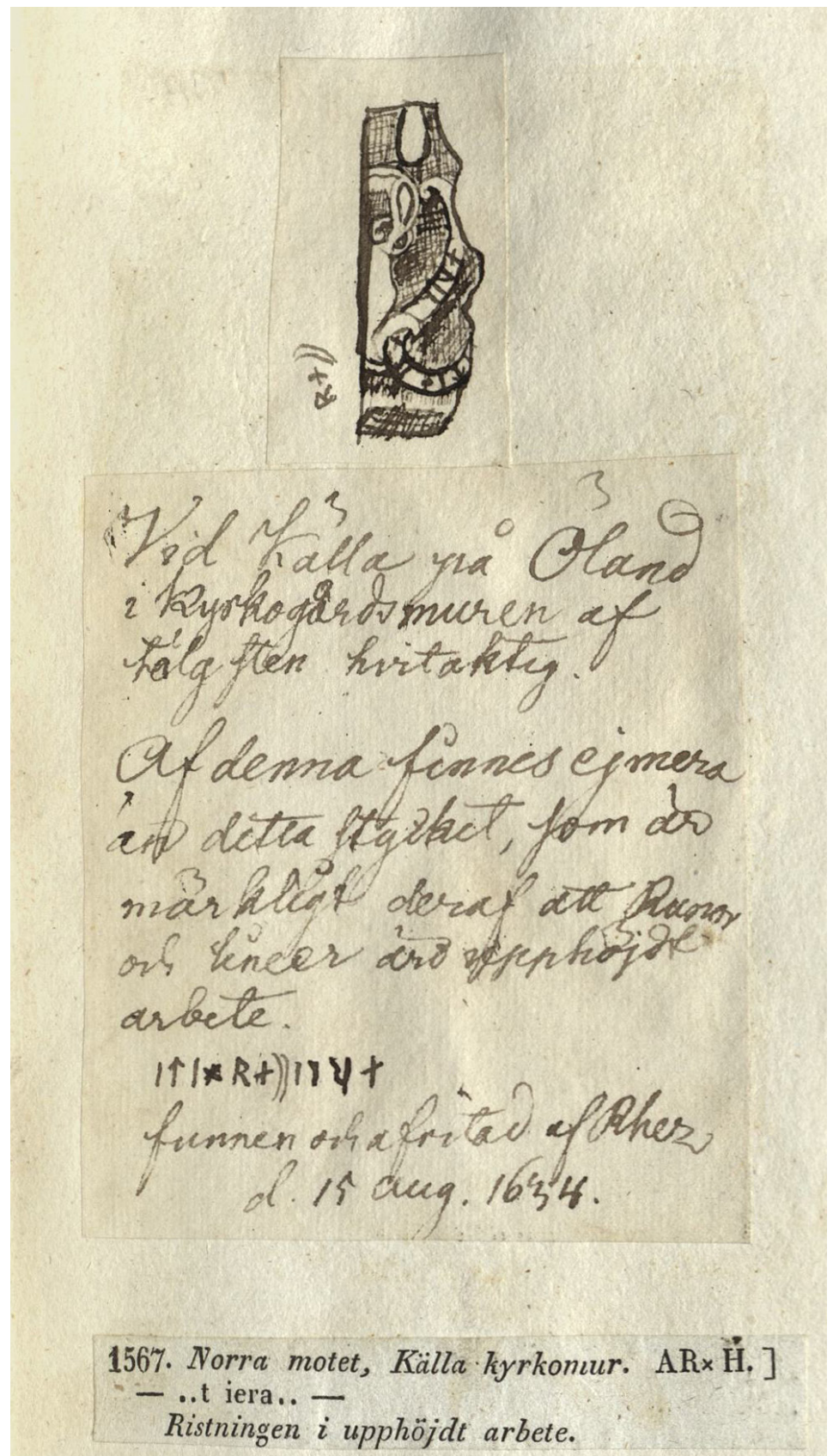

Fig. 2. Anteckningar om Ỏl 57 i Liljegrens "Fullständig Bautil" (ATA)

Futhark 9-10 (2018-2019) 
Det bör samtidigt nämnas att Liljegren för detta fragment inte bara hänvisar till Rhezelius, utan också till C. G. G. Hilfeling. Några uppgifter om denna runsten verkar dock inte finnas i dennes reseberättelser från Öland. En förklaring kan möjligen vara att teckningen i "Fullständig Bautil" har sitt ursprung i Hilfelings samlingar, även om den är en kopia av Rhezelius' avbildning. Handstilen ser dock ut att vara Liljegrens.

Av de uppgifter som hittills har varit kända verkar det alltså som om det under nummer Öl 57 skulle dölja sig delar av två olika runstenar. Det finns dock en förbisedd källa som är mycket klargörande i sammanhanget. IJ. H. Wallmans samling i Nordiska museet (vol. 2, Öland 3) förvaras ett orubricerat häfte som bland annat (på s. 69-73) innehåller blyertsteckningar av ett antal runstensfragment från Källa kyrka. Tydligen är det samma fragment som åsyftas lite längre fram i samma häfte (s. 79): "I [kyrkan] ${ }^{1}$ i Sakristian fanns flera stycken af en med runor ristad, ohuggen kalksten, som alla aftecknades."

Bland teckningarna från Källa kyrka återger Wallman först på s. 69-71 tre fragment av runstenen Öl 56, vilka är identiska med de tre fragment av denna sten som är bevarade i dag (se Källström 2013). Därefter följer på s. $72 \mathrm{f}$. teckningar av ytterligare två runstensfragment. På det ena (fig. 3) finns runorna ... skar. . .t $\times$ rita $\times$ stain $\times$ pị. . .. Detta fragment verkar ha varit sprucket $\mathrm{i}$ tre delar och haft en längd av 0,82 $\mathrm{m}$. Den sneda kanten nedtill ska ha mätt $0,45 \mathrm{~m}$ och motsvarande kant upptill $0,18 \mathrm{~m}$. På det andra fragmentet (fig. 4), som enligt Wallman var 0,59 ×0,45 m stort, ska det ha funnits delar av en runslinga med topparna av tre runor (. . - - t. . .) samt resterna av en bandslinga. Det senare bör ha utgjort fotstycket till en runsten och har av allt att döma haft direkt passning till det förra fragmentet. Detta betyder att den fragmentariska t-runa som finns på båda fragmenten bör vara delar av en och samma runa. Materialet ska ha utgjorts av kalksten och fragmenten ska enligt Wallman ha varit 3 tum dvs. $7,5 \mathrm{~cm}$ tjocka.

Det råder ingen som helst tvekan om att detta är samma sten som Ahlqvist har sett och man förstår då också att ordet "sjal" i hans läsning inte bör återge ordet siāl 'själ', utan måste vara identisk med den runföljd som Wallman har uppfattat som skar. Det intressantaste är dock att fragmenten utan större problem verkar kunna passas ihop med det av Rhezelius avbildade fragmentet (se fig. 5). Wallmans teckningar är mycket summariska och man behöver därför inte ta det så allvarligt att fotstycket inte riktigt får rum. Viktigare är att Wallman på detta fragment förutom

${ }^{1}$ Wallman har här ritat en liten bild på en kyrka. 


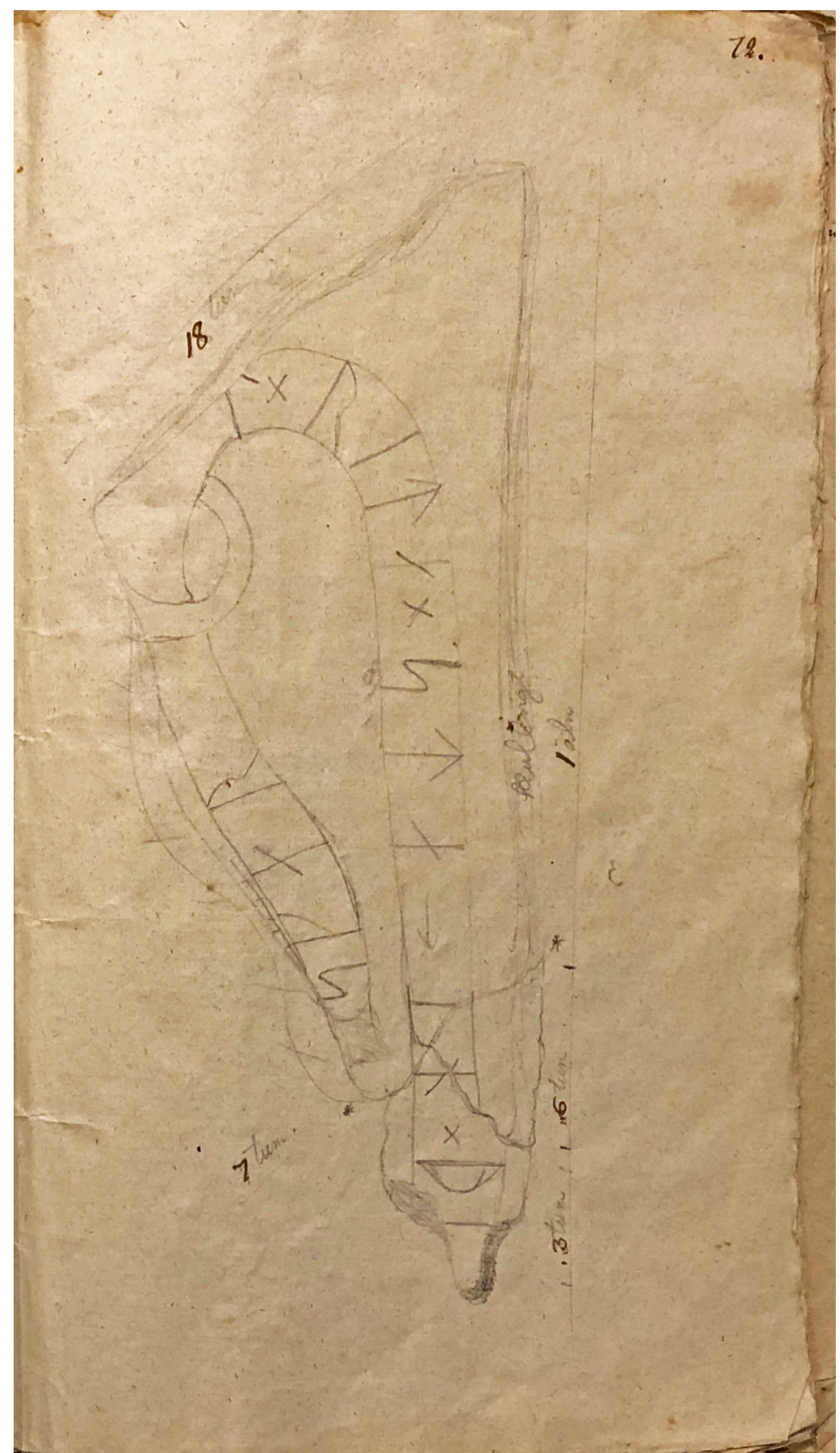

Fig. 3. Fragment av Öl 57. Teckning av J. H. Wallman (Wallmans samling, vol. 2, Öland 3; Nordiska museet, Stockholm).

Futhark 9-10 (2018-2019) 


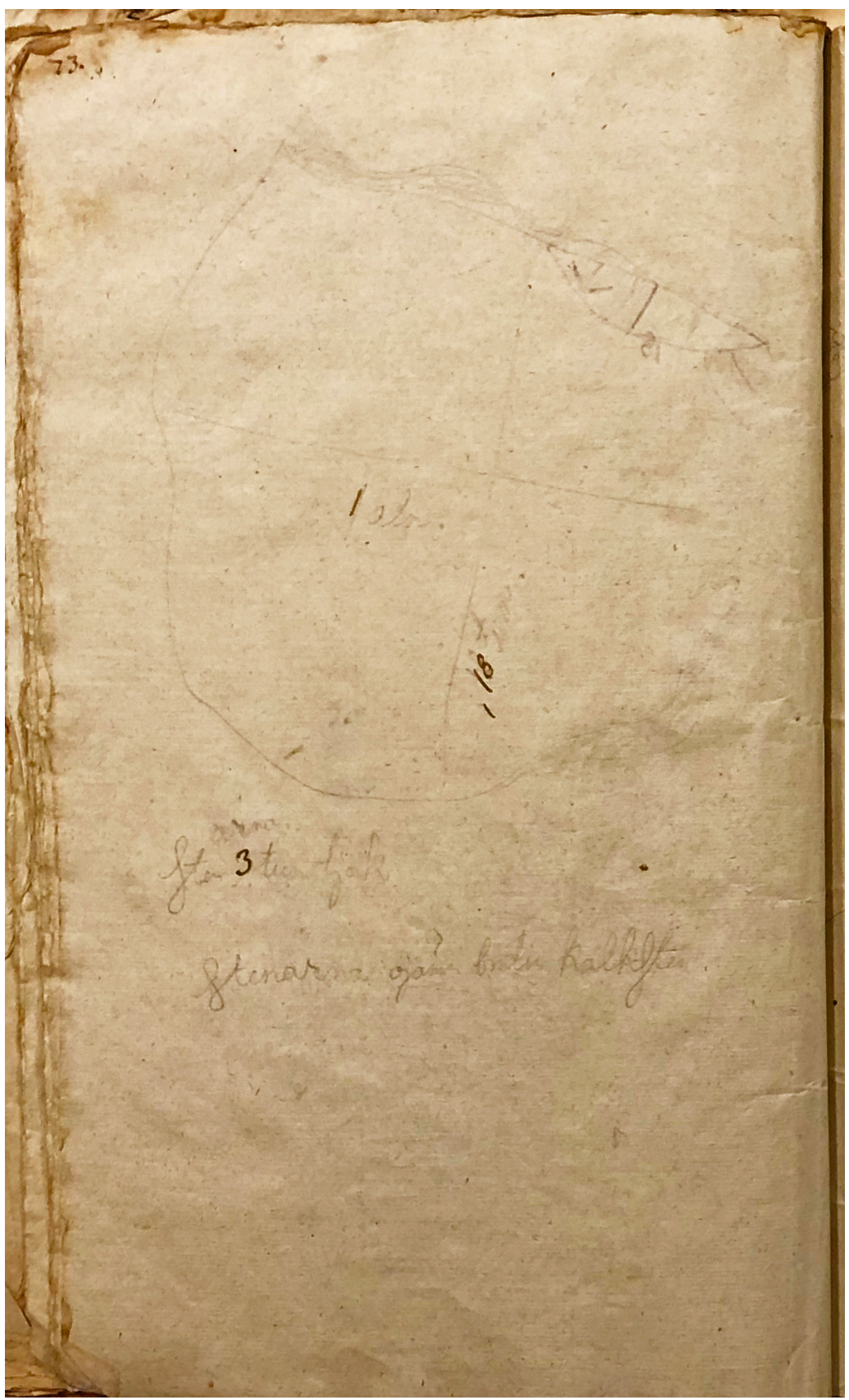

Fig. 4. Ett annat fragment av Öl 57. Teckning av J. H. Wallman (Wallmans samling, vol. 2, Öland 3; Nordiska museet). 


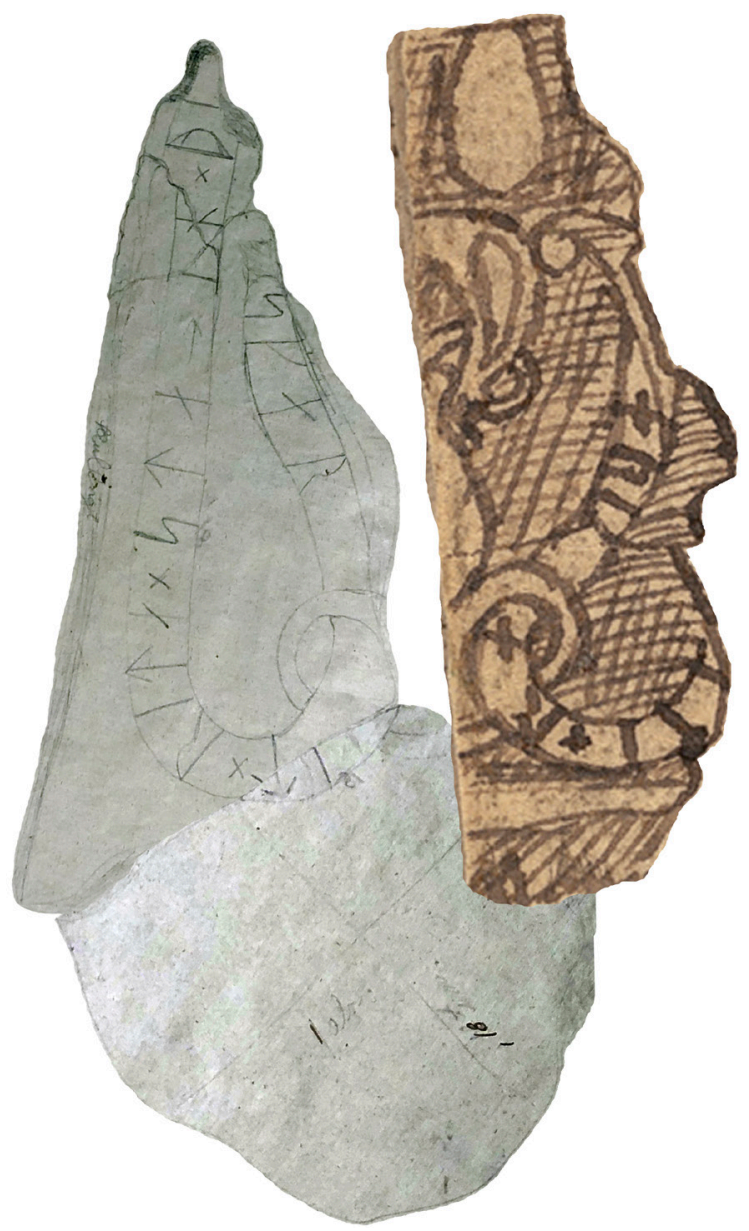

Fig. 5. Rekonstruktion av stenen baserad på Rhezelius' och Wallmans teckningar

runslingan också har antytt en smalare slinga, som korsar denna och av allt att döma är fortsättningen av den bandknut som kan ses på de två andra fragmenten.

Inskriften på Öl 57 kan alltså med en sammanvägning av Wallmans, Ahlqvists och Rhezelius' uppgifter återges på följande sätt:

$$
\text { ...skar... lit } \times \text { rita } \times \text { stain } \times \text { pị } \ldots .--+ \text { ra--a }
$$

De två fragmenten av Ỏl 57 som Wallman avbildade förvarades vid hans besök förmodligen inne i kyrkan. Samtidigt bör det nämnas att han i en 

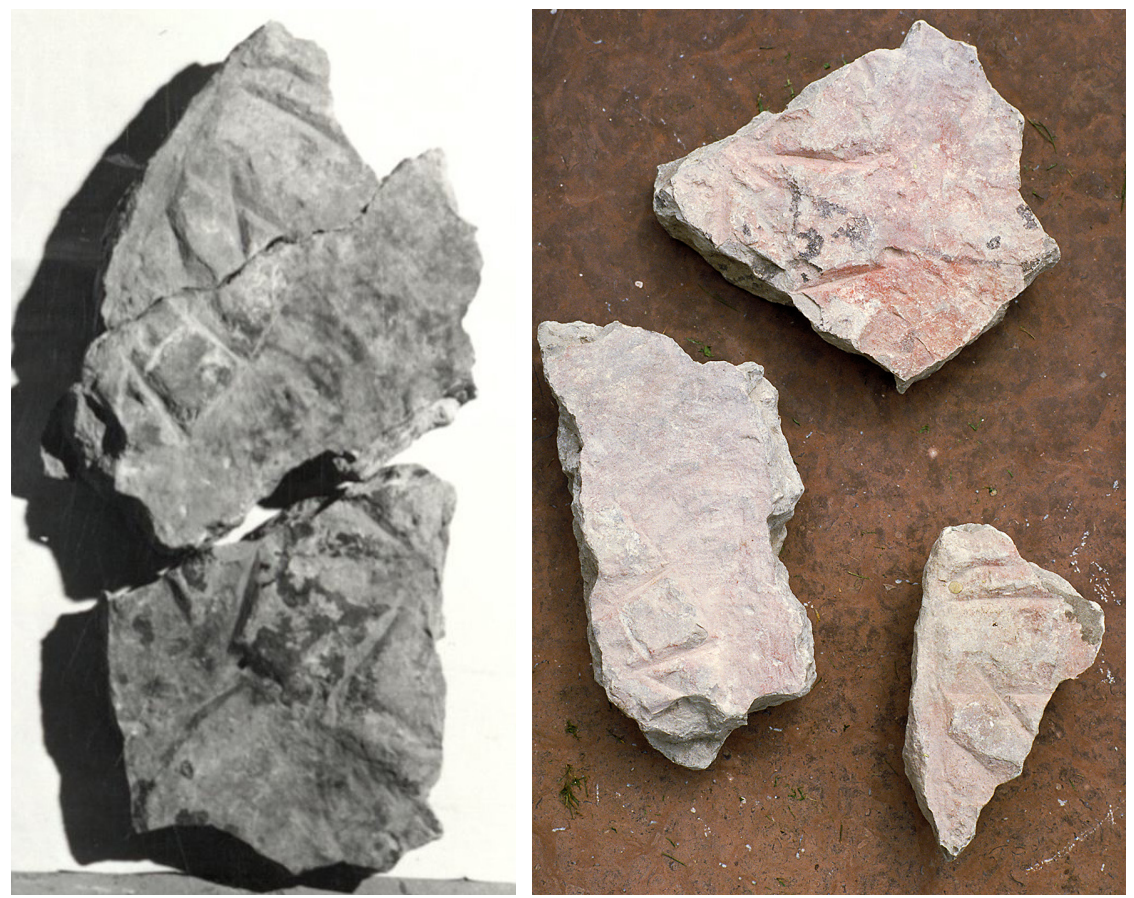

Fig. 6. De bevarade fragmenten av Ỏl 57 (tidigare Öl SvK128;288). Foto (vänster) av Ragnhild Boström, 1960 (ATA), resp. (höger) Bengt A. Lundberg, 1998 (Kulturmiljöbild, Riksantikvarieämbetet).

annan redogörelse för sina undersökningar på Ỏland (vol. 2, Ỏland 2) också har en uppgift om en "Runsten stympad i N. kyrkomuren", som rimligtvis måste avse någon del av denna sten.

1960 påträffade Ragnhild Boström tre mindre runstensfragment i en stenhög i det sydvästra hörnet av Källa ödekyrka (Boström 1960). Eftersom fragmenten var huggna i relief antog hon att det kunde röra sig om delar av den av Rhezelius avbildade stenen, Öl 57 (se även Boström 1969, 288). I Samnordisk runtextdatabas har dock fragmenten som nämnts försiktigtvis fått ett eget signum, Ȯl SvK128;288.

Inskrifterna uppges där vara:

A: $\quad \ldots n i . .$.
B: $\quad \ldots s \cdot k a-. .$.

Denna återgivning bygger på två olika källor. Läsningen av fragment $\mathrm{A}$ är hämtad från Bruce Nilsson (1973, 264), medan texten på fragment B 
kommer från ett registerkort till inventariet för Källa gamla kyrka i ATA (SHM 29400, V: 18a-c). Fragmenten finns även fotograferade av Ragnhild Boström 1960 resp. Bengt A. Lundberg 1998 (fig. 6). Granskar man dessa bilder ser man att de tidigare läsningarna inte kan vara riktiga, något som jag också har kunnat bekräfta vid ett besök i Källa kyrka den 20 juni 2017. Två av fragmenten förvaras visserligen i en monter, som inte kunde öppnas inför mitt besök, men ristningen på dessa är så pass tydlig att den ändå kunde studeras genom monterglaset.

På det fragment som har kallats B i runtextdatabasen och som består av två delar finns runorna ... skar..., vilket svarar direkt mot den första runföljden hos Wallman. På det andra fragmentet kan man utan tvekan läsa runorna it (inte ni). Nedtill framför den första runan finns en kant $\mathrm{i}$ stenytan som kan utgöra resterna av den nedre delen av en bistav till $\mathbf{r}$ och vid den motstående kanten ser man spetsen av bistaven till en $\mathbf{a}$-runa. Av allt att döma står det alltså ... ritạ...., vilket också svarar mot en runföljd på Wallmans teckning. Det råder alltså inget tvivel om att fragmenten är delar av ett av de fragment som Wallman avbildade, även om de bevarade fragmenten är något tunnare $(5,5-6 \mathrm{~cm})$.

Sambandet mellan de nyfunna fragmenten och de fragment som Wallman avbildade visar sig vid närmare efterforskningar inte ha varit helt okänt. I Runverkets handarkiv förvaras en kopia av en sida ur Boström 1969, där det står antecknat med blyerts:

I Wallmans saml, Öland 2, finns skisser av de 'nyfynd' som gjordes 1960. - Det förefaller inte helt uteslutet, att Öl 57 i själva verket omfattar fragment av två olika runstenar, har antikvarien E. Svärdström påpekat.

Kopian är försedd med initialerna TH skrivna med rödpenna och anteckningen har därför förmodligen gjorts av Torulf Holmberg, som var verksam vid Runverket under en period på 1970-talet.

Stenens historia kan alltså rekonstrueras på följande sätt. Det fragment som hittills har varit känt och som fått beteckningen Öl 57 upptäcktes av Rhezelius 1634. Det låg då vid den norra stigluckan vid Källa kyrka, men tycks sedan ha försvunnit. Omkring 1805 påträffades i den norra kyrkomuren ännu ett fragment, som omtalas i Ahlqvists beskrivning. När Wallman besökte Källa kyrka på 1830-talet hade detta fragment brustit i två delar. Det är något oklart om det då fanns vid den norra kyrkogårdsmuren eller om det i likhet med de tre fragmenten av Öl 56 förvarades i sakristian. För det senare talar det faktum att de tre mindre fragmenten hittades inne i kyrkan vid restaureringen 1960 och att man vid samma tillfälle även återfann ett fragment av Öl 56. 
Med de kunskaper som vi har i dag kan alltså inskriften på Ỏl 57 återges på följande sätt (med det inom [ ] efter Rhezelius, Ahlqvist och Wallman):

... skar... [lit $\times]$ ritạ $[\times$ stain $\times$ pị. ...-. + ra--a]

... lèt rētta stæin pe[nna]...

'... lät uppresa denna sten ...'

De första fyra runorna skar bör givetvis vara resterna av ett personnamn, men vilket går inte avgöra. Ett namn Skær skrivet s : kar föreligger möjligen på en östgötsk runsten (Ög 10, se Peterson 2007, 199 s.v. Skær(?)), men betydligt närmare ligger väl att tänka på namnet Huskarl, som förekommer i ett antal uppländska runinskrifter (Peterson 2007, 108 s.v. Hūskarl). Namnet har hittills inte påträffats på Ȯland men utrymmesmässigt verkar detta namn kunna passa in om man tänker sig att en avslutande I-runa har haft sin plats strax före bandknuten. En annan möjlighet är mansnamnet $S k \bar{a} r i$, medan alternativ som exempelvis Skarði eller Skarpi verkar mindre troliga av utrymmesskäl.

Om man undantar det defekta personnamnet har inskriften på Öl 57 nu utökats med fyra tolkningsbara ord, även om samtliga tillhör de allra vanligaste i runvokabulären. Verbet rētta är som bekant mest frekvent i landskapen norr om Mälaren, men uppträder även sporadiskt utanför detta område. Det är tidigare belagt i ett antal runinskrifter på Öland och finns även på den andra runstenen från Källa kyrka (Öl 56). De övriga utgörs av Öl 25 Dröstorp i Sandby (numera Gårdby) socken samt ett antal stenar i Köpings kyrka (Öl 49†, Öl Köping 1, Öl Köping 23, Ȯl Köping 33 och Öl Köping 66). De flesta av dessa stenar ska uppenbarligen räknas till ett sent skede av den vikingatida runstenstraditionen på Öland. Mer anmärkningsvärd är förekomsten på Dröstorpsstenen Ȯl 25, som det på grund av det enkla utförandet med runorna i raka rader kan misstänkas vara en förhållandevis tidig runsten. De ortografiska dragen pekar dock i en annan riktning. Åsrunan betecknar i inskriften /o(:)/ ([ioruik]r Iōru $[l f]_{R}(?),{ }^{2}$. . opur $\left.[b r o ̄] \partial u r\right)$ och äldre /R/ återges antingen med $\mathbf{r}$ eller har lämnats obetecknat (efti æftiR), vilket tyder på att tidsavståndet till de övriga stenarna förmodligen inte är särskilt stort.

Att vi nu kan konstatera att de tre fragmenten i Källa kyrka verkligen är delar av den runsten som Rhezelius såg 1634 är även mycket värdefullt

${ }^{2}$ En sådan tolkning förutsätter en mer lättförklarlig felläsning ( $\mid$ \&NIYR i stället för I $\$ R \cap \Gamma Y R$ ) än det av Sven Söderberg (i SRI, 1: 80) restituerade [iorunt]r Iörundr. - Jan Owe föreslog vid det 5:e runrådet i Uppsala den 15 december 2004 att det kunde handla om ett

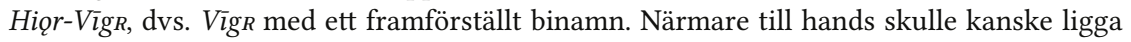
att anta ett * $\bar{o}^{\prime} r \bar{\imath} g R$, men någon namnled - vìg $R$ verkar annars inte finnas belagd.

Futhark 9-10 (2018-2019) 
för bedömningen av själva monumentet. Stenen är som nämnts huggen i relief med en nedbottnad yta innanför runslingan. Boström $(1969,288)$ har noterat att det dessutom finns spår av röd färg på fragmenten, dels på de nedbottnade ytorna, dels i själva runorna. Detta ger ytterligare en förbindelselänk med de runristade stenarna i Köpings kyrka.

Signumet Öl SvK128;288 kan alltså utan någon betänklighet strykas ur framtida versioner av Samnordisk runtextdatabas samtidigt som vi har fått en lösning på gåtan med den avvikande läsningen av Öl 57 hos Liljegren. Hade inte Wallmans teckningar funnits kunde man i likhet med Elisabeth Svärdström ha tolkat fragmenten som delar av två olika runstenar, men av allt att döma utgör de resterna av en och samma sten.

\section{Referenser}

Ahlqvist, Abraham. 1822-27. Ölands historia och beskrifning. 3 vol. Kalmar.

—_. "Samlingar om Öland och Småland (S 84-90)." Uppsala universitetsbibliotek, Uppsala.

ATA = Antikvarisk-topografiska arkivet, Riksantikvarieämbetet, Stockholm.

Boström, Ragnhild. 1960. Skrivelse till Riksantikvarien den 2 september 1960 (ATA dnr 5633/60) [med tillhörande kalkeringar med anteckningar i fotografisamlingen].

— . 1969. Källa kyrkor, Åkerbo härad, Öland. Sveriges kyrkor, 128. Stockholm.

Inventarieförteckning för Källa gamla kyrka, SHM inv. nr 29400, V: 18a-c (ATA dnr 4022/71).

Källström, Magnus. 2013. "Korrigering av läsningen på runstenen Öl 56 från Källa ödekyrka, Öland.” Otryckt rapport (ATA dnr 3.5.1-03803-2013). http:// kulturarvsdata.se/raa/samla/html/6326

$\mathrm{L}+$ nummer $=$ runinskrift publicerad i Liljegren 1833.

Liljegren, Johan Gustaf. 1833. Run-urkunder: Aftryck för Run-Forskningens Vänner. Stockholm.

—. u.å.: "Fullständig Bautil." 7 vol. Manuskript i ATA.

Ljung, Cecilia. 2016. Under runristad häll. Vol. 1, Tidigkristna gravmonument $i$ 1000-talets Sverige; vol. 2, Katalog över tidigkristna gravmonument. Stockholm Studies in Archaeology, 67.1-2. Stockholm.

Nilsson, Bruce E. 1973. The Runic Inscriptions of Öland. Ann Arbor, Michigan. (University Microfilms International.)

Owe, Jan. 2002. Runfynden vid Köpings kyrka. Bro.

Peterson, Lena. 2007. Nordiskt runnamnslexikon. 5. utg. Uppsala.

SHM = Statens historiska museum, Stockholm.

SRI = Sveriges runinskrifter. Olika författare; publicerade av Kungl. Vitterhets

Historie och Antikvitets Akademien. 14 vol. hittills. Stockholm, 1900-.

SRI, 1 = Ölands runinskrifter, av Sven Söderberg och Erik Brate (1900-06). 
SRI, 2 = Östergötlands runinskrifter, av Erik Brate (1911-18).

Wallmans samling. Nordiska museets arkiv, Stockholm.

Òg + nummer = runinskrift publicerad i Óstergötlands runinskrifter, dvs. SRI, 2.

Öl + nummer = runinskrift publicerad i Ölands runinskrifter, dvs. SRI, 1.

Ȯl Köping + nummer = runinskrift från Köpings kyrka publicerad i Owe 2002.

Ỏl SvK128;288 = runinskrift från Källa kyrka publicerad i Boström 1969.

\section{Summary}

A resurrected runestone from Källa Old Church on Öland (Öl 57)

When Jonas Håkansson Rhezelius visited Öland on his antiquarian journey in 1634 he illustrated an incomplete runestone at Källa Church with only a few runes left but with ornamentation cut in high relief. This now lost stone has entered Ölands runinskrifter as Öl 57 based on Rhezelius's sketch. In the 1820s Abraham Ahlqvist reported another runestone fragment with a longer and more legible inscription including parts of a raiser formula, which he renders with latin letters as "lit. rita. stai. - . - sjal. - - - -". The relationship with the fragment recorded by Rhezelius has remained unclear, but a couple of drawings by J. H. Wallman in the archive of the Nordic Museum (Nordiska museet) show that they probably matched each other. It is also demonstrated that some small rune-inscribed fragments that were discovered in the church in 1961 are remnants of the larger fragment(s) seen by Ahlqvist and Wallman. Based on the runes on the preserved fragments and earlier accounts, the inscription is read and interpreted as follows: ...skar... [lit $\times]$ rita $[\times$ stain $\times$ pị....-- + ra$-a]$ ". . had this stone raised ...". The name of the commemorator may have been $[H \bar{u}]$ skar $[l]$, but could also have been for example Skar[ði] or Skar[pi]. 
